\title{
A 15-year survey of reproductive efficiency of Standardbred and Finnhorse trotters in Finland - descriptive results
}

\author{
Terttu Katila*1, Tiina Reilas², Kaisa Nivola3 ${ }^{3}$ Terttu Peltonen ${ }^{4}$ and Anna-Maija Virtala ${ }^{5}$
}

\begin{abstract}
Background: The major horse breeds in Finland are the Finnhorse (FH) and the American Standardbred (SB). The foaling rates of the FH have consistently been lower than those of the SB. During the last years, a decreasing trend in foaling rates of both breeds has been observed. The purpose of this study was to describe and compare the structure of these two mare populations for age, reproductive history and mating type. In addition, changes over the years were studied that could explain the decline in foaling rates.

Methods: In Finland, the mating statistics and foaling rates per stallion are published yearly by Suomen Hippos, which is the Finnish trotting and breeding association authorized by the EU. The studied material was the electronic breeding data of Suomen Hippos in 1991-2005 which contained 69180 cases (one mare bred in one year with one stallion), 20 168 mares, 2230 stallions and 5397 stud managers. The effect of mare age and type, mating type and changes during the study period were examined separately for FH and SB using SAS 9.1 for descriptive statistical analyses (frequencies, percentages, means, standard deviations and confidence intervals). The outcome of the last mating per season (foal or not) was used in the calculation of the foaling rates.
\end{abstract}

Results: The FH mares were on average one year older and belonged to the older age groups more often than the SB mares. Ageing decreased foaling rates and even more in $\mathrm{FH}$; the foaling rates were the following: young $\mathrm{FH} 68.6$ and SB $72.1 \%$, middle-aged FH 66.1 and SB 71.9\%, ageing FH 61.2 and SB 68.4\%, and very old FH 52.8 and SB 61.8\%. The foaled mares were more frequent in the SB (45\%) than in the $\mathrm{FH}(37 \%)$, but the barren and rested mares were more common in the FH. Natural mating was more commonly practiced in the $\mathrm{FH}$ as compared to the SB. The foaling rates decreased from 1991 to 2005 in SB from 75.1 to 65.9\% and in FH from 66.5 to 60.8\%. For both breeds, the proportion of young mares decreased and the proportion of very old mares increased over the years. Similarly, the proportion of foaled mares in both breeds decreased and the proportion of barren mares increased during the study period. In both breeds, insemination (Al) by transported cooled semen increased, diminishing the on-site Al in the SB and the natural mating in the $\mathrm{FH}$.

Conclusions: The results of this study suggest that mare age and type and mating type all affect foaling rates and that the structural differences in the mare populations can explain differences in the foaling rates between the horse breeds and between the time periods.

\section{Background}

Profitable horse breeding requires general information about the reproductive traits of horses, which horse breeders can then utilize in decision making. However, most research in equine reproduction has focused on

* Correspondence: terttu.katila@helsinki.fi

${ }^{1}$ Department of Production Animal Medicine, University of Helsinki, Paroninkuja 20, 04920 Saarentaus, Finland

Full list of author information is available at the end of the article individual animals, physiology and pathology. Only one epidemiological study based on a large number of horses (535 746 matings) has been published [1]. This French study comprised several breeds: the Thoroughbred (TB), Anglo-Arab, Selle Francais, French Trotter and the coldblooded French breeds. An Australian study compared the reproductive efficiency of the TB and the Standardbred (SB) horses [2]. Whereas several reports on TB 
farms have been published [3-12], less has been published on other breeds: Hannoverians [13], Icelandic horses [14], feral horses [15] and different horse breeds in the USA [16] and in Finland [17].

In Finland, the mating statistics and foaling rates per stallion are published yearly by Suomen Hippos, which is the Finnish trotting and breeding association authorized by the EU. During the recent years, a decreasing trend in foaling rates has been suspected.

Finland has its own horse breed, the Finnish cold blood, the Finnhorse (FH). This breed is of universal type and is mostly used for sports. The average height at withers is $156 \mathrm{~cm}$ and the weight is $550 \mathrm{~kg}$. The present population is 19500 horses from which 200 are breeding stallions and 2300 brood mares. Furthermore, approximately 1 300 foals are born yearly [18].

Annual reports of Suomen Hippos show higher foaling rates for the $\mathrm{SB}$ than for the $\mathrm{FH}$.

The total population of the SB in Finland is about 25 000 making it the largest horse breed in Finland. According to the data base of Suomen Hippos, $64 \%$ of the SB mares were born in Finland and 36\% were imported. Annually, 90 stallions and 2600 mares are used for breeding and 1600 foals are born. In addition, semen from approx. 50 foreign stallions is imported both as cooled and frozen, mainly from Sweden, Italy, Germany and USA. The use of imported semen has increased from 50 to approximately 500 mares per year; half of the mares are inseminated with frozen semen.

The Finnish studbooks and horse registers are kept and administered by Suomen Hippos. To maintain these records, the stallion managers have to report all matings of the breeding season to one of the sixteen local horse breeding associations by the end of October. If the mating has not been reported, the foals are not registered and they are not allowed to race. As a consequence, one can assume that practically all the matings of the trotter mares and births of the foals are reported. Moreover, since 1990, local breeding associations submit the mating records in digital form to the central database of Suomen Hippos.

The objective of this study was to examine the Finnish horse breeding data for possible differences between the two breeds and for changes in the foaling rates through the years. The frequency distributions and foaling rates are reported for each breed, year, time period, age, mare type and mating type. The aim was to seek for any structural changes and differences in the mare populations or mating methods that could explain the possible differences between the breeds and years.

\section{Methods}

The data originates from all the reported inseminations of the FH and SB trotter mares in Finland during the years 1991-2005. For this project, the records in the database of Suomen Hippos were imported to Excel'.

One case was defined as one mare bred in one year with one stallion. Only the outcome of the last mating per season (foal or not) was used. The original data consisted of 70238 cases; 1002 cases were excluded from the data because the mare type could not be defined. These excluded mares had entered the database in the first years of the digital registration and their foaling history was unknown. Mares over 25 years old $(\mathrm{n}=28)$ were all excluded owing to the small likelihood of their conceiving at this advanced age. One-year-old mares were also excluded $(n=25)$ because their mating was not planned but accidental, and therefore, only mares which foaled had been reported. Another group excluded from this study was the only three FH mares artificially inseminated (AI) with frozen semen. After these exclusions, the final number of cases was 69 180. It is important to note that the same mares, stallions and stallion managers occur several times because the data covers 15 years.

\section{Definitions}

Foaling rate was used as the measure of reproductive efficiency. In the horse breeding literature, the foaling rate is used for the proportion of mares (\%) that have foaled the following year of all mares mated. The Finnish database also includes matings per cycle, but since they had not been consistently reported, the foaling rate was considered to be a more reliable measure.

In the database of Suomen Hippos, the result of the breeding is divided into seven categories. In this study, the categories filly, colt, dead foal and foal died after birth were assigned the value 1 (foaled), and the categories barren, aborted and mare died pregnant were given the value 0 (not foaled).

The change in foaling rates through the years was studied both from year to year and in longer time periods. The 15 years in the study were divided in four time periods (TP): TP1 = $1991-1994$, TP2 = $1995-1998$, TP3 = $1999-2002$ and TP4 $=2003-2005$.

Mares were divided into four age groups: young (2 - 9 years), middle-aged (10 - 13 years), ageing (14 - 16 years), and very old (17 - 25 years). The different mare types in the data were 1) maiden (never mated), 2) barren (mated earlier, but aborted or did not conceive), 3) rested (not mated after the last foaling), and 4) foaled (mare with a live or dead foal).

The type of breeding was categorised as 1) on-site AI (mare inseminated with fresh semen at the same station where the stallion was resident), 2) AI using transported semen (mare inseminated with cooled semen transported to another station or home stable), 3) AI using frozen semen (only in SB), and 4) natural mating. 


\section{Statistics}

After the data had been checked for possible mistakes, typing errors and outliers, they were transported to the SAS 9.1 statistical package (SAS Institute Inc.) for descriptive statistical analyses. The data were described using frequencies, percentages, means, and standard deviations. The $95 \%$ binomial confidence intervals for the percentages were calculated using the FREQ procedure.

\section{Results}

There were altogether 69180 breeding cases and 102615 cycles, out of which 33699 breeding cases/49 339 cycles were for the FH mares and 35481 cases/53 276 cycles for the SB mares. The data included 20143 mares: $9633 \mathrm{FH}$ and $10510 \mathrm{SB}$. About 30\% of the mares appeared in the data more than once. The same FH mare appeared in the data a maximum of 24 times and the same SB mare 18 times. About 3\% of the mares (594 mares) had more than 10 breeding seasons.

There were altogether 2230 stallions (1 $201 \mathrm{FH}$ and $1029 \mathrm{SB})$ and 5397 stallion managers. Stallion managers were divided according to the breed of the stallion: 3472 stallion managers had FH stallions and 2190 SB stallions.

\section{Mares}

The young mares were the largest age group, but whereas they comprised $47 \%$ of the SB mare population, they represented only $37 \%$ of the $\mathrm{FH}$ mares. Correspondingly, the $\mathrm{FH}$ occurred more frequently in the very old mare group than the SB (13 versus $8 \%$ ). The proportions of middleaged mares were $33 \%$ in $\mathrm{FH}$ and $32 \%$ in SB and the proportions of ageing mares 17 and 13\%, respectively. The median ages were 11 years for the $\mathrm{FH}$ and 10 years for the SB.

Foaled mares were the largest mare type in both breeds, but more frequent in the SB (45\%) than in the FH (37\%). On the other hand, barren and rested mares were more common in the $\mathrm{FH}$ (26 and 15\%) than in the SB (21 and $12 \%)$. The proportions of maiden mares were $21 \%$ in $\mathrm{FH}$ and $22 \%$ in SB.

When the age within the mare types was considered, the young SB mares were more frequent in the categories of maiden, barren and foaled mares than the FH; no difference was detected in the rested mares (Table 1). In the middle-aged and ageing groups, the maiden $\mathrm{FH}$ mares were more common than the SB mares.

In the whole material, half of the $\mathrm{FH}$ were naturally mated, whereas only one quarter of the SB mares were. In the $\mathrm{SB}$, the on-site $\mathrm{AI}$ was the most common mating type (41\%), as compared to $28 \%$ of the $\mathrm{FH}$ mares; natural mating was most common for the $\mathrm{FH}$ population. Transported semen was used more frequently to the foaled mares as compared to the other mare types (Table 2).

\section{Changes over the study period}

The structure of the Finnish broodmare population changed during the study period. For instance, the proportion of young mares decreased over the years in both breeds (Table 3); the proportion of young mares in the $\mathrm{FH}$ group fell from 40 to $30 \%$ between 1991 and 2005 and those in the SB group fell from 54 to $41 \%$ during the same period. In addition, during the same years, the proportion of the very old mares changed from 11 to $16 \%$ in the $\mathrm{FH}$ and from 6 to $11 \%$ in the SB.

Another finding is that over the years, the proportion of foaled mares decreased from 46 to $30 \%$ in the $\mathrm{FH}$ and from 53 to $39 \%$ in the SB. The proportion of barren mares increased in both breeds, but no changes were observed in the maiden mares (Table 4).

In mating types, the change in favour of insemination with transported semen was quite marked in both breeds (FH from 14 to $31 \%$ and SB from 15 to $36 \%$ ) (Table 5). On-site AI decreased in SB (from 50 to $36 \%$ ) but stayed the same in FH. The use of natural mating became less popular in both breeds: from 55 to $40 \%$ in $\mathrm{FH}$ and from 31 to $20 \%$ in SB. The use of frozen semen increased slightly (from 4 to $8 \%$ ) in SB.

\section{Foaling rate}

The foaling rate in the whole material was $68 \%: 64 \%$ in the $\mathrm{FH}$ and $71 \%$ in the SB. There was a lowering trend in the foaling rates from $71 \%$ (66\% in $\mathrm{FH}$ and $75 \%$ in $\mathrm{SB}$ ) in 1991 to $63 \%$ (61\% in $\mathrm{FH}$ and 66\% in SB) in 2005 (Figure 1). Foaling rates declined with increasing age in both breeds (Figure 2). Barren mares displayed the lowest foaling rates (Figure 3). In both breeds, the rested and foaled mares in young and middle-aged groups were the most fertile while the very old maidens were the least fertile (Table 6). Moreover, the very old and ageing barren and the ageing maiden $\mathrm{FH}$ mares showed low foaling rates.

The least successful mating type of the FH was natural mating and the most successful was the on-site AI. For the $\mathrm{SB}$, the lowest foaling rate was found in the frozen semen group and the highest rate in the on-site AI group (Figure 4).

\section{Discussion}

The data analysed showed declining foaling rates during the study period. Moreover, it was very obvious that the foaling rates of the $\mathrm{FH}$ were lower than those of the SB.

\section{Differences between $\mathrm{FH}$ and SB}

The FH exhibited lower foaling rates than the SB. It is possible that the $\mathrm{FH}$ has genetically inferior fertility as compared to the SB, but the differences in the management of the mares and stallions, in both the age structure of the horses and in the proportions of the different mare types, may also explain the difference in foaling rates. 
Table 1: Proportions (\% and $95 \% \mathrm{Cl}$ ) of different mare age groups in different mare types for Finnhorses (FH) and Standardbreds (SB) in years 1991 - 2005.

\begin{tabular}{|c|c|c|c|c|c|c|c|c|}
\hline & \multicolumn{2}{|c|}{ Maiden } & \multicolumn{2}{|c|}{ Barren } & \multicolumn{2}{|c|}{ Rested } & \multicolumn{2}{|c|}{ Foaled } \\
\hline & $\%$ & $95 \% \mathrm{Cl}$ & $\%$ & $95 \% \mathrm{Cl}$ & $\%$ & $95 \% \mathrm{Cl}$ & $\%$ & $95 \% \mathrm{Cl}$ \\
\hline \multicolumn{9}{|l|}{ Young } \\
\hline $\mathrm{FH}$ & 83.2 & $82.3-84.1$ & 25.0 & $24.1-25.9$ & 26.3 & $25.1-27.5$ & 23.8 & $23.0-24.5$ \\
\hline SB & 90.5 & $89.8-91.1$ & 35.9 & $34.8-37.0$ & 25.6 & $24.3-26.9$ & 37.0 & $36.3-37.8$ \\
\hline \multicolumn{9}{|c|}{ Middle-aged } \\
\hline $\mathrm{FH}$ & 14.7 & $13.9-15.5$ & 34.9 & $33.9-35.9$ & 39.2 & $37.8-40.5$ & 38.8 & $37.9-39.6$ \\
\hline SB & 8.2 & $7.6-8.8$ & 36.7 & $35.6-37.8$ & 43.4 & $42.0-44.9$ & 39.3 & $38.5-40.0$ \\
\hline \multicolumn{9}{|l|}{ Ageing } \\
\hline $\mathrm{FH}$ & 1.7 & $1.4-2.0$ & 21.7 & $20.9-22.6$ & 20.3 & $19.2-21.4$ & 22.0 & $21.2-22.7$ \\
\hline SB & 1.1 & $0.8-1.3$ & 15.9 & $15.1-16.7$ & 18.7 & $17.5-19.8$ & 15.1 & $14.6-15.7$ \\
\hline \multicolumn{9}{|l|}{ Very old } \\
\hline $\mathrm{FH}$ & 0.3 & $0.2-0.5$ & 18.3 & $17.5-19.1$ & 14.3 & $13.4-15.3$ & 15.5 & $14.8-16.1$ \\
\hline SB & 0.3 & $0.2-0.4$ & 11.6 & $10.8-12.3$ & 12.3 & $11.3-13.3$ & 8.6 & $8.2-9.0$ \\
\hline $\mathrm{nFH}$ & \multicolumn{2}{|c|}{6987} & \multicolumn{2}{|c|}{8870} & \multicolumn{2}{|c|}{5236} & \multicolumn{2}{|c|}{12606} \\
\hline $\mathrm{n} S \mathrm{~B}$ & \multicolumn{2}{|c|}{7869} & \multicolumn{2}{|c|}{7401} & \multicolumn{2}{|c|}{4355} & \multicolumn{2}{|c|}{15856} \\
\hline
\end{tabular}

Age groups: Young $=2-9$ years, Middle-aged $=10-13$ years, Ageing $=14-16$ years, Very old $=17-25$ years.

Langlois and Blouin [1] reported lower fertility for coldblooded horses, but pointed out that this may be related to the differences in reporting foals. Management plays an important role: the intensively and professionally managed TB mares have very high pregnancy and foaling rates [9]. In contrast, the $\mathrm{FH}$ owners may represent a more traditional horse owner because natural mating was more commonly practiced for the FH than for the SB. Foaling rates after natural mating were lower than after on-site AI which was more common in the SB. The FH

Table 2: Proportions (\% and $95 \% \mathrm{Cl}$ ) of different mating types in different mare types for Finnhorses (FH) and Standardbreds (SB) in years 1991 - 2005.

\begin{tabular}{|c|c|c|c|c|c|c|c|c|}
\hline & \multicolumn{2}{|c|}{ Maiden } & \multicolumn{2}{|c|}{ Barren } & \multicolumn{2}{|c|}{ Rested } & \multicolumn{2}{|c|}{ Foaled } \\
\hline & $\%$ & $95 \% \mathrm{Cl}$ & $\%$ & $95 \% \mathrm{Cl}$ & $\%$ & $95 \% \mathrm{Cl}$ & $\%$ & $95 \% \mathrm{Cl}$ \\
\hline \multicolumn{9}{|c|}{ On-site Al } \\
\hline $\mathrm{FH}$ & 29.3 & $28.2-30.3$ & 28.1 & $27.1-29.0$ & 27.8 & $26.6-29.0$ & 27.4 & $26.6-28.2$ \\
\hline SB & 42.4 & $41.3-43.5$ & 44.2 & $43.1-45.3$ & 40.5 & $39.0-41.9$ & 39.8 & $39.0-40.6$ \\
\hline \multicolumn{9}{|c|}{ Transported semen } \\
\hline $\mathrm{FH}$ & 19.5 & $18.5-20.4$ & 18.0 & $17.2-18.8$ & 19.9 & $18.8-21.0$ & 27.1 & $26.3-27.9$ \\
\hline SB & 25.5 & $24.6-26.5$ & 24.9 & $23.9-25.9$ & 26.8 & $25.5-28.2$ & 32.9 & $32.1--33.6$ \\
\hline \multicolumn{9}{|c|}{ Frozen semen } \\
\hline SB & 5.3 & $4.8-5.8$ & 4.8 & $4.3-5.3$ & 3.7 & $3.2-4.3$ & 5.5 & $5.1-5.9$ \\
\hline \multicolumn{9}{|c|}{ Natural cover } \\
\hline $\mathrm{FH}$ & 51.3 & $50.1-52.5$ & 53.9 & $52.9-55.0$ & 52.3 & $50.9-53.6$ & 45.5 & $44.7--46.4$ \\
\hline SB & 26.8 & $25.8-27.8$ & 26.1 & $25.1-27.1$ & 29.0 & $27.6-30.3$ & 21.8 & $21.2-22.5$ \\
\hline $\mathrm{n} F \mathrm{H}$ & \multicolumn{2}{|c|}{6987} & \multicolumn{2}{|c|}{8870} & \multicolumn{2}{|c|}{5236} & \multicolumn{2}{|c|}{12606} \\
\hline $\mathrm{n}$ SB & \multicolumn{2}{|c|}{7869} & \multicolumn{2}{|c|}{7401} & \multicolumn{2}{|c|}{4355} & \multicolumn{2}{|c|}{15856} \\
\hline
\end{tabular}


Table 3: Proportions ( $\%$ and $95 \% \mathrm{Cl}$ ) of different mare age groups in different time periods for Finnhorses (FH) and Standardbreds (SB).

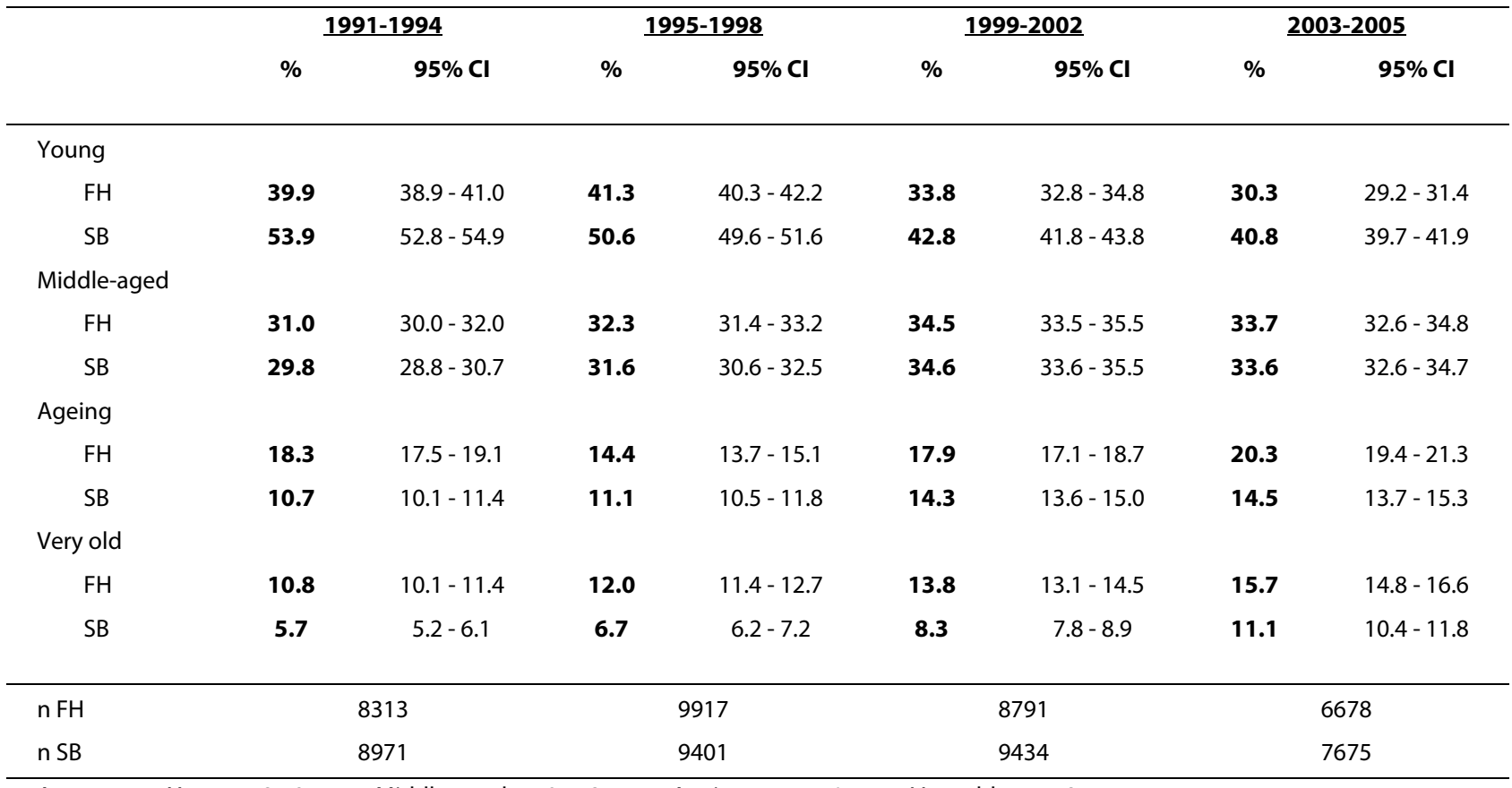

Age groups: Young $=2-9$ years, Middle-aged $=10-13$ years, Ageing $=14-16$ years, Very old $=17-25$ years.

mares are probably more often owned and handled by amateurs who might not even sell their foals. The breeding and foal fees are lower for the $\mathrm{FH}$ which may also exert an effect on the efforts to get a foal.
The FH mares were on average one year older than the SB mares, which is likely to cause some difference in the foaling outcome. Many studies report the negative effect of ageing of mares on the rates of pregnancy and foaling and on the pregnancy loss $[1,3,6,8-12,16,19-21]$. It is well

Table 4: Proportions (\% and $95 \% \mathrm{Cl}$ ) of different mare types in different time periods for Finnhorses (FH) and Standardbreds (SB).

\begin{tabular}{|c|c|c|c|c|c|c|c|c|}
\hline & \multicolumn{2}{|c|}{ 1991-1994 } & \multicolumn{2}{|c|}{ 1995-1998 } & \multicolumn{2}{|c|}{ 1999-2002 } & \multicolumn{2}{|c|}{ 2003-2005 } \\
\hline & $\%$ & $95 \% \mathrm{Cl}$ & $\%$ & $95 \% \mathrm{Cl}$ & $\%$ & $95 \% \mathrm{Cl}$ & $\%$ & $95 \% \mathrm{Cl}$ \\
\hline \multicolumn{9}{|l|}{ Maiden } \\
\hline $\mathrm{FH}$ & 20.1 & $19.3-21.0$ & 21.8 & $21.0-22.6$ & 19.1 & $18.3-19.9$ & 22.1 & $21.1-23.1$ \\
\hline $\mathrm{SB}$ & 20.3 & $19.5-21.2$ & 25.1 & $24.2-25.9$ & 20.5 & 19.7 - 21.4 & 22.8 & $21.9-23.8$ \\
\hline \multicolumn{9}{|l|}{ Barren } \\
\hline $\mathrm{FH}$ & 24.7 & $23.8-25.6$ & 24.7 & $23.8-25.5$ & 27.3 & $26.4-28.3$ & 29.5 & $28.4-30.6$ \\
\hline SB & 18.5 & $17.7-19.3$ & 18.9 & $18.1-19.7$ & 22.2 & $21.3-23.0$ & 24.4 & $23.5-25.4$ \\
\hline \multicolumn{9}{|l|}{ Rested } \\
\hline $\mathrm{FH}$ & 9.6 & $9.0-10.3$ & 16.0 & $15.3-16.7$ & 18.3 & $17.4-19.1$ & 18.6 & $17.7-19.5$ \\
\hline $\mathrm{SB}$ & 8.1 & $7.6-8.7$ & 13.0 & $12.3-13.6$ & 14.2 & $13.5-14.9$ & 13.9 & $13.1-14.7$ \\
\hline \multicolumn{9}{|l|}{ Foaled } \\
\hline $\mathrm{FH}$ & 45.6 & $44.5-46.6$ & 37.5 & $36.6-38.5$ & 35.3 & $34.3-36.3$ & 29.8 & $28.7-30.9$ \\
\hline $\mathrm{SB}$ & 53.0 & $52.0-54.1$ & 43.1 & $42.1-44.1$ & 43.1 & $42.1-44.1$ & 38.8 & $37.7-39.9$ \\
\hline $\mathrm{nFH}$ & \multicolumn{2}{|c|}{8313} & \multicolumn{2}{|c|}{9917} & \multicolumn{2}{|c|}{8791} & \multicolumn{2}{|c|}{6678} \\
\hline $\mathrm{n} S \mathrm{SB}$ & \multicolumn{2}{|c|}{8971} & \multicolumn{2}{|c|}{9401} & \multicolumn{2}{|c|}{9434} & \multicolumn{2}{|c|}{7675} \\
\hline
\end{tabular}


Table 5: Proportions ( $\%$ and $95 \% \mathrm{Cl}$ ) of different mating types in different time periods for Finnhorses (FH) and Standardbreds (SB).

\begin{tabular}{|c|c|c|c|c|c|c|c|c|}
\hline & \multicolumn{2}{|c|}{ 1991-1994 } & \multicolumn{2}{|c|}{ 1995-1998 } & \multicolumn{2}{|c|}{ 1999-2002 } & \multicolumn{2}{|c|}{$\underline{2003-2005}$} \\
\hline & $\%$ & $95 \% \mathrm{Cl}$ & $\%$ & $95 \% \mathrm{Cl}$ & $\%$ & $95 \% \mathrm{Cl}$ & $\%$ & $95 \% \mathrm{Cl}$ \\
\hline \multicolumn{9}{|c|}{ On-site Al } \\
\hline $\mathrm{FH}$ & 30.8 & $29.8-31.8$ & 25.7 & $24.8-26.6$ & 27.2 & $26.2-28.1$ & 29.2 & $28.1-30.3$ \\
\hline SB & 50.1 & $49.0-51.1$ & 42.6 & $41.6-43.6$ & 36.5 & $35.5-37.5$ & 35.7 & $34.6-36.8$ \\
\hline \multicolumn{9}{|c|}{ Transported semen } \\
\hline $\mathrm{FH}$ & 14.0 & $13.2-14.7$ & 19.8 & $19.0-20.6$ & 25.4 & $24.5-26.3$ & 30.7 & $29.6-31.8$ \\
\hline SB & 15.4 & $14.7-16.2$ & 26.4 & $25.5-27.3$ & 38.1 & $37.1-39.1$ & 36.1 & $35.1-37.2$ \\
\hline \multicolumn{9}{|c|}{ Frozen semen } \\
\hline SB & 3.9 & $3.5-4.3$ & 4.7 & $4.3-5.1$ & 4.4 & $4.0-4.8$ & 7.8 & $7.2-8.4$ \\
\hline \multicolumn{9}{|c|}{ Natural cover } \\
\hline $\mathrm{FH}$ & 55.2 & $54.2-56.3$ & 54.5 & $53.5-55.5$ & 47.4 & $46.4-48.5$ & 40.1 & $39.0-41.3$ \\
\hline SB & 30.7 & $29.7-31.6$ & 26.3 & $25.4-27.2$ & 21.0 & $20.1-21.8$ & 20.3 & $19.4-21.2$ \\
\hline $\mathrm{nFH}$ & \multicolumn{2}{|c|}{8313} & \multicolumn{2}{|c|}{9917} & \multicolumn{2}{|c|}{8791} & \multicolumn{2}{|c|}{6678} \\
\hline $\mathrm{n}$ SB & \multicolumn{2}{|c|}{8971} & \multicolumn{2}{|c|}{9401} & \multicolumn{2}{|c|}{9434} & \multicolumn{2}{|c|}{7675} \\
\hline
\end{tabular}

established that fertility starts to decrease in middle age: according to Allen et al. > 9 years [11], Laing and Leech > 10 years [3], Hutton and Meacham $>12$ years [16], Hemberg et al. > 13 years [10], Morris and Allen, Sanderson and Allen, and Bosh et al. $\geq 14$ years $[6,9,12]$, and Hearn et al. > 15 years [8]. In our data, the FH were overrepresented by about 10 percentage points in the two older age classes as compared to the SB. Moreover, the foaling rates in these two higher age groups were lower than in the two younger age groups for both breeds. The FH had foaling rates that were 4-5 percentage points lower than the SB in all age groups, except in the very old mare group where the difference was 9 percentage points higher. Since the FH have lower foaling rates at all ages, age alone may not explain the difference between the breeds, although the higher mean age of the $\mathrm{FH}$ certainly contributes to the difference.

Factors that affect a mare's chance of foaling are the age and the reproductive history of the mare. There were less foaled mares in the $\mathrm{FH}$ than in the SB. Correspondingly, the barren mare group was larger in the $\mathrm{FH}$ than in the SB. Foaled mares are the most fertile group [9], with the exception of the mares bred in foal heat which have lower pregnancy rates [5,9] and higher pregnancy loss rates $[9,19]$ than the mares mated in subsequent heats. Maiden mares are also highly fertile $[8,9,11,12]$. In contrast, barren mares have the lowest pregnancy rates and the highest pregnancy loss rates $[6,8,11,12,19]$. In all mare types, the $\mathrm{FH}$ had 4-5 percentage points lower foaling rates than the SB, but for barren mares, the difference was 10 percentage points. Although mare type alone may not explain the difference between the $\mathrm{FH}$ and $\mathrm{SB}$, it may be a contributing factor to the difference, since the distribution of mares into mare types was less favourable in the $\mathrm{FH}$ than in the SB.

The interaction of age and mare type has to be considered as well. Particularly in the maiden mare group, the FH mares were older than those of the SB. Moreover, the old maiden mares have been shown to be the least fertile of all when inseminated with frozen semen [22]. The FH mares seemed to enter the barren mare category at a younger age than the SB mares. In all, the FH mare population differed from the SB population both in terms of age and mare type and age within the mare type. All these differences were unfavourable to the $\mathrm{FH}$ and can at least partly explain the lower foaling rates of the $\mathrm{FH}$ mares.

\section{Decreasing foaling rates}

The foaling rates showed a decline over the years, which was particularly noticeable since 2000. The decrease in the foaling rate from 1991 to 2005 was over 10 percentage points for the SB, which was greater than for the $\mathrm{FH}$. In fact, the foaling rate difference between the breeds has diminished from the initial $10 \%$ to $5 \%$. The foaling rates (for live foal) in TB breeding increased from 1983 to 1998 by 5 percentage points [9] but decreased from 1998 to 2002 by 3 percentage points $[9,11]$. During the decade 1989-1999 in France, foaling rates increased in all breeds, but more so for the cold-blooded horses, which were less productive to start with; the TB breed progressed very little [1]. However, these studies are from a different time period as the present study and therefore cannot be 
Table 6: Foaling rates in different mare types and age groups for Finnhorses (FH) and Standardbreds (SB) in years 1991 2005.

\begin{tabular}{|c|c|c|c|c|c|c|}
\hline & \multicolumn{4}{|c|}{ FH } & \multicolumn{2}{|c|}{ SB } \\
\hline & $\mathbf{n}$ & foaling rate $\%$ & $95 \% \mathrm{Cl}$ & $\mathbf{n}$ & $\begin{array}{c}\text { foaling rate } \\
\%\end{array}$ & $95 \% \mathrm{Cl}$ \\
\hline Young & 12405 & & & 16756 & & \\
\hline Maiden & & 67.9 & $66.7-69.1$ & & 71.7 & $70.6-72.7$ \\
\hline Barren & & 63.9 & $61.9-65.9$ & & 69.4 & $67.7-71.2$ \\
\hline Rested & & 71.9 & $69.6-74.3$ & & 76.4 & $73.9-78.9$ \\
\hline Foaled & & 72.1 & $70.5-73.8$ & & 72.9 & $71.8-74.1$ \\
\hline Middle-aged & 11066 & & & 11479 & & \\
\hline Maiden & & 59.9 & $56.9-62.9$ & & 67.9 & $64.3-71.5$ \\
\hline Barren & & 59.1 & $57.4-60.1$ & & 68.7 & $67.0-70.5$ \\
\hline Rested & & 68.9 & $66.9-70.9$ & & 73.8 & $71.9-75.8$ \\
\hline Foaled & & 70.7 & $69.4-72.0$ & & 73.1 & $72.0-74.2$ \\
\hline Ageing & 5880 & & & 4470 & & \\
\hline Maiden & & 39.7 & $30.9-48.4$ & & 63.9 & $53.5-74.2$ \\
\hline Barren & & 54.4 & $52.2-56.6$ & & 66.2 & $63.4-68.9$ \\
\hline Rested & & 67.9 & $65.1-70.7$ & & 69.8 & $66.6-72.9$ \\
\hline Foaled & & 64.4 & $62.6-66.1$ & & 69.3 & $67.4-71.1$ \\
\hline Very old & 4348 & & & 2776 & & \\
\hline Maiden & & 37.5 & $18.1-56.9$ & & 52.2 & $31.8-72.6$ \\
\hline Barren & & 47.8 & $45.4-50.2$ & & 58.8 & $55.5-62.1$ \\
\hline Rested & & 53 & $49.4-56.6$ & & 65.4 & $61.4-69.5$ \\
\hline Foaled & & 57 & $54.8-59.2$ & & 62.4 & $59.8-65.0$ \\
\hline
\end{tabular}

Age groups: Young $=2-9$ years, Middle-aged $=10-13$ years, Ageing $=14-16$ years, Very old $=17-25$ years.

directly compared. Finland has seen the same trend, with the foaling rates increasing in the $1980 \mathrm{~s}$ because of the new reproductive technology, the on-site AI and ultrasonography.

During the follow-up time, the proportion of young mares decreased both in the $\mathrm{FH}$ and the $\mathrm{SB}$, and correspondingly the proportions of other age classes increased. Thus, the development in the mares' age has been unfavourable and may contribute to the decline in foaling rates. Furthermore, the proportion of foaled mares diminished (16 percentage points for $\mathrm{FH}$ and 14 for $\mathrm{SB}$ ) and the proportion of barren mares increased in both breeds ( 5 percentage points for $\mathrm{FH}$ and 6 for SB). During this time, the proportion of the rested FH mares doubled and the proportion of these increased in the SB mares by almost 5 percentage points. These represent major changes from the most fertile mare groups to the less fertile mare types.

The structure of the brood mare population for age and reproductive history has not been studied in other breeds with the exception of the TB. Allen and his coworkers published three studies about reproductive efficiency in TB in Newmarket area. These publications contain pregnancy and foaling rates and their analysis from mating seasons 1982-3, 1998 and 2002 [6,9,11]. This allows also us to look at changes over the years and compare the distributions of ages (Table 7) and mare types (Table 8) between TB, SB, and FH. The division of mares into age categories in the English studies was slightly different from ours but the results are still comparable. The time periods were not exactly the same, since the first English study was carried out 10 years earlier than our first time period.

The age structure of $\mathrm{TB}$ and $\mathrm{SB}$ was similar, but $\mathrm{FH}$ were much older. While the mares in our material became older, the TB population was younger in 1998 than earlier or later. Maybe this is also the reason for the higher pregnancy and foaling rates reported for the season 1998 as compared to $1982-3$ and 2002. However, a clear ageing of the TB mare population from 1982-3 to 2002 was evident similar to our observations. 


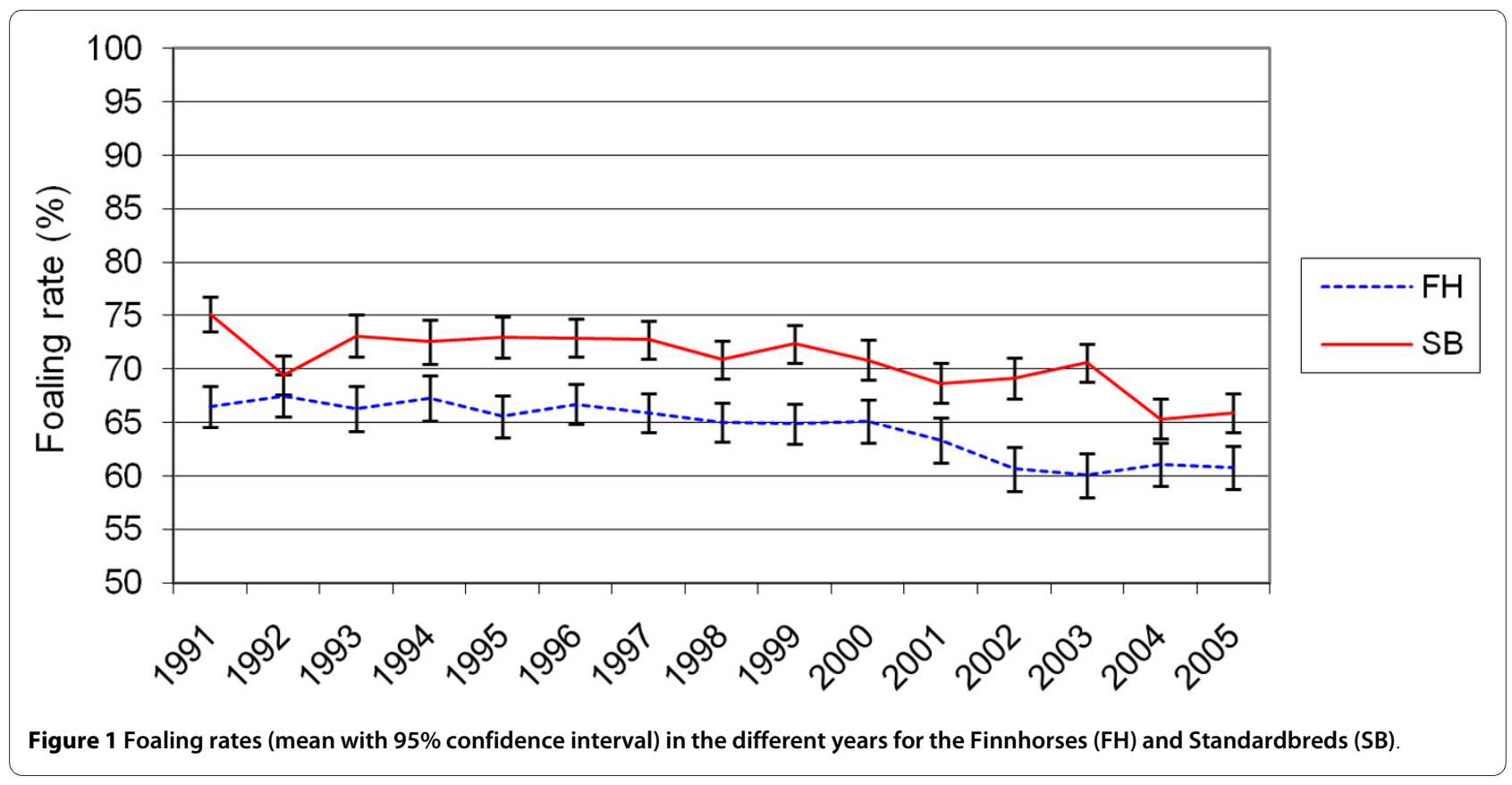

The proportion of foaling mares throughout these years was approximately 10 percentage points higher in TB than in SB and 20 percentage points higher than in $\mathrm{FH}$ (Table 8). The maiden mare population was smaller in TB than in our trotters but the barren mare group was similar in size. It is unclear, why rested mares were lacking in the TB studies from 1982-3 and 2002, but since they comprised only $1.5 \%$ in 1998 , it can be concluded that they did not represent a large group. This group was much higher in the SB and FH trotters. This may reflect the professionalism in TB breeding: once the mare has started as a brood mare, it is consistently bred each year. In Finland, many breeders have one or two mares which they breed only for their own purposes, not for sale. Economical constraints may also play a role; in Finland the

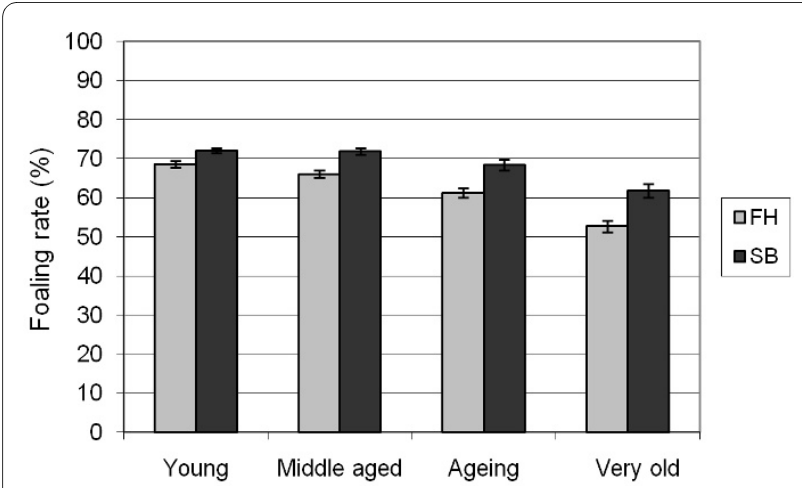

Figure 2 Foaling rates (mean with $95 \%$ confidence interval) in the different age groups for the Finnhorses (FH) and Standardbreds (SB) in the years 1991 - 2005. Age groups: Young = 2 - 9 years, Middle-aged $=10-13$ years, Ageing $=14-16$ years, Very old $=17-25$ years. foal prices and selling prospects have sometimes been so low that it is better not to breed the mare again for a year or two.

During the first half of the 1980 s natural mating gave way to the on-site AI in Finland. In the second half of the $1980 \mathrm{~s}$, transported semen started to replace the on-site AI. This development - a decrease in natural mating and in the on-site $\mathrm{AI}$ and an increase in transported semen continued during the study period of 1991-2005. In the $\mathrm{FH}$, the proportion of the on-site AI did not change much, but while the proportion of transported semen doubled, the proportion of natural mating decreased by 15.1 percentage points. Moreover, the proportion of transported semen doubled in the SB, but both the onsite AI (-14 percentage points) and natural mating (-10 percentage points) decreased. In addition, the use of fro-



Figure 3 Foaling rates (mean with $95 \%$ confidence interval) in the different mare types for the Finnhorses $(\mathrm{FH})$ and Standardbreds (SB) in the years $1991-2005$ 




Figure 4 Foaling rates (mean with $95 \%$ confidence interval) in the different mating types for the Finnhorses (FH) and Standardbreds (SB) in the years $1991-2005$

zen semen increased by 4 percentage points. Almost $44 \%$ of the SB mares are inseminated using techniques where the individual stallion differences in the sperm survival during storage can result in a large variation in the foaling rates.

Natural cover - which is the only allowed mating method for the TB - results in very high rates of pregnancy and foaling in the TB industry [9-12], but in other breeds where the AI is allowed and used, higher pregnancy rates have usually been reported for the AI than for the natural mating. For instance, Langlois and Blouin [1] demonstrated the highest foaling rates for the on-site AI. The next best method was free pasture mating (not practiced in Finland); similar results were yielded for transported semen, frozen semen and in-hand natural mating. For both breeds in Finland, the on-site AI was the best method; foaling rates after the use of natural mating and transported semen were similar, but lower as compared to the on-site AI, and frozen semen resulted in the lowest foaling rate. The differences in foaling rates between the on-site $\mathrm{AI}$ and the transported semen were almost 3 percentage points for the $\mathrm{FH}$ and 5 percentage points for the SB.

The high pregnancy and foaling rates of the $\mathrm{TB}$ as a result of natural cover are in conflict with the results achieved in other breeds. Probably the high value of the breeding stock and foals creates pressures, but also offers opportunities for veterinarians and stud managers to intensively manage, control and treat mares. The AI as such may not be any better than natural mating, but its use requires the use of a veterinarian and as a result, the mares are carefully controlled and examined.

\section{Foaling rate vs. pregnancy rates}

Unfortunately, the original goal to use the pregnancy rate per cycle as the fertility measure was not possible because of frequent missing data. Pregnancy rate per cycle reflects the true fertility of the mare and stallion, whereas the seasonal pregnancy rate can be greatly improved by persistent trying, hard work and good management. Foaling rate, on the other hand, includes the effect of the pregnancy losses. Although this does not necessarily reflect innate fertility, it is the best economical measure. One example for the difference between the fertility measures can be taken from the study of Morris and Allen [9]: the pregnancy rates per cycle were $55.3 \%$ for barren mares and $61.4 \%$ for foaling mares, the respective seasonal pregnancy rates were 92.4 and $85.6 \%$, and foaling rates 88.8 and $81.2 \%$. The barren mares may be valuable problem mares which get more attention and benefit

Table 7: Age distribution of Thoroughbreds (TB), Standardbreds (SB) and Finnhorses (FH).

\begin{tabular}{|c|c|c|c|c|}
\hline Mating seasons & Young (\%) & Middle-aged (\%) & Ageing (\%) & Very old (\%) \\
\hline \multicolumn{5}{|l|}{ TB } \\
\hline $1982-3$ & 51.8 & 30.0 & 14.6 & 3.6 \\
\hline 1998 & 53.5 & 29.7 & 14.0 & 2.8 \\
\hline 2002 & 45.1 & 32.8 & 17.0 & 4.3 \\
\hline \multicolumn{5}{|l|}{ SB } \\
\hline $1991-4$ & 53.9 & 29.8 & 10.7 & 5.7 \\
\hline $1995-8$ & 50.6 & 31.6 & 11.1 & 6.7 \\
\hline $1999-2002$ & 42.8 & 34.6 & 14.3 & 8.3 \\
\hline \multicolumn{5}{|l|}{$\mathrm{FH}$} \\
\hline $1991-4$ & 39.9 & 31.0 & 18.3 & 10.8 \\
\hline $1995-8$ & 41.3 & 32.3 & 14.4 & 12.0 \\
\hline $1999-2002$ & 33.8 & 34.5 & 17.9 & 13.8 \\
\hline
\end{tabular}

Young = 3-8 $y$ for TB and 2-9 $y$ for SB and FH; middle-aged = 9-13 y for TB and 10-13 y for SB and FH; ageing = 14-18 $y$ for TB and 14-16 $y$ for $\mathrm{SB}$ and $\mathrm{FH}$; very old $=>18$ for $\mathrm{TB}$ and $17-25$ for $\mathrm{SB}$ and $\mathrm{FH}$.

TB data 1982-3 from Sanderson and Allen (1987), 1998 from Morris and Allen (2002), and 2002 from Allen et al. $(2007)[6,9,11]$. 
Table 8: Distribution of different mare types in Thoroughbreds (TB), Standardbreds (SB) and Finnhorses (FH).

\begin{tabular}{|c|c|c|c|c|}
\hline Mating seasons & Maiden (\%) & Barren (\%) & Foaling (\%) & Rested (\%) \\
\hline \multicolumn{5}{|l|}{ TB } \\
\hline $1982-3$ & 11.9 & 24.7 & 63.4 & N.R. \\
\hline 1998 & 16.2 & 16.8 & 65.5 & 1.5 \\
\hline 2002 & 17.7 & 24.7 & 57.6 & N.R. \\
\hline \multicolumn{5}{|l|}{ SB } \\
\hline $1991-4$ & 20.3 & 18.5 & 55.0 & 8.1 \\
\hline $1995-8$ & 25.1 & 18.9 & 43.1 & 13.0 \\
\hline 1999-2002 & 20.5 & 22.2 & 43.1 & 14.2 \\
\hline \multicolumn{5}{|l|}{$\mathrm{FH}$} \\
\hline $1991-4$ & 20.1 & 24.7 & 45.6 & 9.6 \\
\hline $1995-8$ & 21.8 & 24.7 & 37.5 & 16.0 \\
\hline $1999-2002$ & 19.1 & 27.3 & 35.3 & 18.3 \\
\hline
\end{tabular}

Barren mare category includes also aborted mares. N.R. = not reported.

TB data 1982-3 from Sanderson and Allen (1987), 1998 from Morris and Allen (2002), and 2002 from Allen et al. $(2007)[6,9,11]$.

from veterinary treatments, but also have a risk to lose the pregnancy. In an Australian study, the pregnancy rate per cycle was significantly higher in TB than in SB, but the seasonal pregnancy rates were the same, which was explained by the longer breeding season in SB industry [2]. One can speculate whether the low foaling rates of barren and old mares in Finnish trotters, particularly FH, as compared with those of TB could be explained by deficient veterinary care and reluctance of owners to invest money in the treatments. In the intensive and professional TB industry, veterinarians are an integral part of the business, but in Finland this is not as self-explanatory.

Another example can be taken from the use of frozen semen. There per cycle pregnancy rates are typically low (20-50\%), but the seasonal pregnancy rates are close to fresh semen AI (60-90\%) [23]. In our data, the foaling rate after frozen semen AI was $64 \%$, which was 6 percentage points lower than for transported semen, but presumably the pregnancy rates per cycle would have differed more. Pregnancy rate per cycle is a more sensitive indicator when the efficiency and economy of breeding is evaluated.

\section{Sources of error}

Our results are prone to some errors due to several steps and several people handling the data starting from the level of accuracy among the stallion holders providing the first information.

It is also possible that some stallion owners purposely left some of the non-pregnant mares out of the book in an attempt to get better pregnancy results for their stallion. Moreover, not all breedings are necessarily reported, because stallion managers might not be aware of the pur- pose of reporting matings in all heats, not just the last heat of the season.

\section{Conclusions}

For the future, it is very important that the data collection is precise, reliable and as inclusive as possible. This means that all matings in all cycles should be recorded. As the foaling rate is not a very sensitive indicator for fertility and the pregnancy rate per cycle or per first mating would be much better, their use should be made possible. Furthermore, the stud farms should give the breeding reports in real time or at least once a month to avoid the possibility of leaving out data on the non-successful matings.

Precise, accurate and timely breeding data are necessary to detect the possible changes in fertility and breeding efficiency. For this reason, the horse breeding industry needs to be informed in good time about the possible threats to the efficiency of horse breeding.

The descriptive results of this study suggest that factors such as age and type of the mare as well as mating type all have important effects on foaling rates. Moreover, structural differences exist between the two horse breed populations which may explain the differences in foaling rates. Structural differences in the mare populations have taken place during the study period and they are likely to explain the declining foaling rates. A more in-depth statistical multivariable analysis of the data considering the hierarchy of the breeding structure would reveal the relative significance of the different variables.

\section{Competing interests}

The authors declare that they have no competing interests. 


\section{Authors' contributions}

KN imported, checked, corrected and analysed the material and drafted the figures. A-M V instructed and supervised the description and statistical analysis of the data and participated in the revision of the manuscript. TR actively participated in the revision and writing of the manuscript. TP represented the organisation that owned the data and was actively involved in the planning of the research and made comments to the text. TK was the initiator and leader of the project and had the major responsibility for writing and finalizing the manuscript. All authors read and approved the final manuscript.

\section{Authors' information}

$\mathrm{KN}$ is the co-owner and chief veterinarian of the largest stud farm in Finland concentrating mainly on SB breeding. She is enrolled in a PhD programme at the University of Helsinki. A-M V, Ph.D., is a university lecturer in veterinary epidemiology at the University of Helsinki. TR, Ph.D., is a researcher in equine reproduction in the Equine Research of MTT Agrifood Research Finland. TP, MSC, is responsible for the animal breeding department in Suomen Hippos, the central horse organisation in Finland. TK, Ph.D., is professor in animal reproduction at the University of Helsinki working mainly with equine reproduction.

\section{Acknowledgements}

The authors wish to thank the Ministry of Agriculture and Forestry for funding this study, the Suomen Hippos for generously providing the data, and statistician Tero Vahlberg for his work.

\section{Author Details}

'Department of Production Animal Medicine, University of Helsinki, Paroninkuja 20, 04920 Saarentaus, Finland, 2MTT Agrifood Research Finland, Opistontie 10, 32100 Ypäjä, Finland, ${ }^{3}$ Kallelan oriasema, Isonummentie 212, 23600 Kalanti, Finland, ${ }^{4}$ Suomen Hippos, Tulkinkuja 3, 02650 Espoo, Finland and ${ }^{5}$ Department of Veterinary Biosciences, University of Helsinki, P.O. Box 66, 00014 Helsinki, Finland

Received: 21 October 2009 Accepted: 14 June 2010

Published: 14 June 2010

\section{References}

1. Langlois B, Blouin C: Statistical analysis of some factors affecting the number of horse births in France. Reprod Nutr Dev 2004, 44:583-595.

2. Reproductive efficiency of horses in Australia [http:// www.qvequine.com.au/breeding efficiency.htm] 9.1.2009

3. Laing JA, Leech FB: The frequency of infertility in Thoroughbred mares. J Reprod Fertil 1975:307-310.

4. Osborne VE: Factors influencing foaled percentages in Australian mares. J Reprod Fertil 1975:477-483.

5. Sullivan JJ, Turner PC, Self LC, Gutteridge HB, Bartlett DE: Survey of reproductive efficiency in the Quarter-horse and Thoroughbred. $J$ Reprod Fertil 1975:315-318

6. Sanderson MW, Allen WR: Reproductive efficiency of Thoroughbred mares in the United Kingdom. 9th edition. Edited by: Huntigton T. Proc Bain Fallon Memorial Lectures, AEVA, Sydney :31-41.

7. Brück I, Anderson GA, Hyland JH: Reproductive performance of thoroughbred mares on six commercial stud farms. Aust Vet J 1993, 70:299-303.

8. Hearn P, Bonnett B, Samper J: Factors influencing pregnancy and pregnancy loss on one thoroughbred farm. 39th Ann Conv Am Assoc Equine Pract 1993:161-163.

9. Morris LHA, Allen WR: Reproductive efficiency of intensively managed Thoroughbred mares in Newmarket. Equine Vet J 2002, 34:51-60.

10. Hemberg E, Lundeheim N, Einarsson S: Reproductive performance of Thoroughbred mares in Sweden. Reprod Dom Anim 2004, 39:81-85.

11. Allen WR, Brown L, Wright M, Wilsher S: Reproductive efficiency of Flatrace and National Hunt Thoroughbred mares and stallions in England. Equine vet J 2007, 39:438-445.

12. Bosh KA, Powell D, Shelton B, Zent W: Reproductive performance measures among Thoroughbred mares in central Kentucky, during the 2004 mating season. Equine vet J 2009, 41:883-888.

13. Merkt $H$, Jacobs K-O, Klug E, Aukes E: An analysis of stallion fertility rates (foals born alive) from the breeding documents of the Landgestüt Celle over a 158-year period. J Reprod Fertil 1979:73-77.
14. Davies Morel MCG, Gunnarson V: A survey of the fertility of Icelandic stallions. Anim Reprod Sci 2000, 64:49-64.

15. Keiper R, Houpt K: Reproduction in feral horses: An eight-year study. Am J Vet Res 1984, 45:991-995.

16. Hutton CA, Meacham TN: Reproductive efficiency on fourteen horse farms. J Anim Sci 1968, 27:434-438.

17. Katila T: Effects of hormone treatments, season, age and type of mares on ovulation, twinning and pregnancy rates of mares inseminated with fresh and frozen semen. Pferdeheilkunde 2003, 19:619-624.

18. Jalostustilastot Suomen Hippos 2008 [http://www.hippos.fi/hippos/ jalostus ia kasvatus/Jalostustilastot.php]. 24.4.2009

19. Chevalier-Clément F: Pregnancy loss in the mare. Anim Reprod Sci 1989, 20:231-244

20. Carnevale EM, Ginther OJ: Relationship of age to uterine function and reproductive efficiency in the mare. Theriogenology 1992, 37:231-246.

21. McDowell KJ, Powell DG, Baker CB: Effect of book size and age of mare and stallion on foaling rates in thoroughbred mares. J Equine Vet $\mathrm{SC}$ 1992, 1:364-367.

22. Samper JC: Management and fertility of mares bred with frozen semen. Anim Reprod Sci 2001, 68:219-228.

23. Barbacini S, Marchi V, Zavaglia G: Equine frozen semen: results obtained in Italy during the 1994-1997 period. Equine vet Educ 1999, 11:109-112.

doi: 10.1186/1751-0147-52-40

Cite this article as: Katila et al., A 15-year survey of reproductive efficiency of Standardbred and Finnhorse trotters in Finland - descriptive results Acta Veterinaria Scandinavica 2010, 52:40

\section{Submit your next manuscript to BioMed Central and take full advantage of:}

- Convenient online submission

- Thorough peer review

- No space constraints or color figure charges

- Immediate publication on acceptance

- Inclusion in PubMed, CAS, Scopus and Google Scholar

- Research which is freely available for redistribution
C) Biomed Central 